CASE STUDY

\title{
Students With Disabilities as Partners: A Case Study on User Testing an Accessibility Website
}

*Kate Brown, Equity and Inclusion Office, McMaster University, Canada

Alise de Bie, Paul R. MacPherson Institute for Leadership, Innovation and Excellence in Teaching, McMaster University, Canada

Akshay Aggarwal, Ryan Joslin, Sarah Williams-Habibi, and Vipusaayini Sivanesanathan, McMaster University, Canada

Contact: brownk33@mcmaster.ca

\section{ABSTRACT}

While partnership is widely encouraged as an approach to advancing the inclusion of disabled postsecondary students, these collaborations are largely taking place between staff offices and failing to meaningfully integrate disabled students as partners. In this case study, we describe the successes and challenges of a pilot project where students and staff with and without disabilities worked together to user test our university's accessibility website, to which faculty/staff are regularly directed for resources on making their teaching more accessible. We achieved our goal of compiling results into a report for decision-makers in order to advance campus-wide technological accessibility. Instead of primarily treating disabled students as lacking capacities and requiring programmatic intervention to succeed in the university, a partnership approach validates and draws on disabled students' specific expertise and experience to make institutional change.

\section{KEYWORDS}

student-staff partnership, disability, accessibility, user testing, websites

Access to online information and communication technologies has been recognized as a basic human right by the United Nations' (2006) Convention on the Rights of Persons with Disabilities and as necessary for promoting the full inclusion of disabled citizens. The right to accessible online spaces is further encoded in Ontario's provincial accessibility legislation, the Accessibility for Ontarians with Disabilities Act (AODA) (2005), which seeks to create an accessible Ontario (Canada) by 2025 through compliance with accessibility standards, including 
those related to technological environments. Website accessibility is especially crucial within a university context where teaching and learning resources are being increasingly distributed online (Bates, 2017; Wang \& Schrager, 2017). In response to these legislative and ethical demands, postsecondary institutions are urged to develop university-wide web accessibility strategies (Lewis, Yoder, Riley, So, \& Yusufali, 2007).

Similar to built physical environments, websites are often designed by non-disabled people with non-disabled users in mind. It is thus essential that accessible web development and user testing take place to ensure the inclusion of disabled users, especially those who use assistive technology (AT) in daily life (e.g., screen reading programs, read-aloud browser applications, speech-to-text programs, screen magnifiers, specialized mice). User (or usability) testing by disabled people using AT-that is, the assessment of online platforms for technical functionality, ease of navigability, logical organization, and clarity of content-not only improves the AT user experience, but the experience of all other users as well (Interactive Accessibility, 2015; Sekovanić, Vukovac, \& Podbojec, 2012). In order to ensure user testing is completed appropriately, it is important to recruit users with a wide range of disabilities and lived familiarity with different assistive technologies (Bevan \& Petrie, 2009; Interactive Accessibility, 2018).

\section{PROJECT DETAILS}

This pilot project involved students and staff with and without disabilities working together as partners to user test our institutional accessibility website (https://accessibility.mcmaster.ca), to which faculty/staff are regularly directed for resources on making their teaching more accessible. Our goal was to compile results into a report for the office responsible for designing many of our university's websites and other decision-makers in order to advance campus-wide technological accessibility. Two staff from the campus equity office, an assistive technologist and web accessibility specialist from our disability office, and four student partners comprised the project team. Five members of the team identified as disabled (i.e., as having learning, physical, and mental health disabilities and chronic pain/illness). Students were paid for their work by our teaching and learning centre's student partners program.

Practically, the user testing process involved building and executing test cases using specific assistive technologies/software to see whether or not the technology would interface successfully with the website (Digital Education Strategies, 2018). If students could navigate the test function with the assistive technology (e.g., click on the zoom in/out button and have the page zoom in), the test case passed. If not, it failed. Based on this testing, we found that the website design assumed the user was reading and navigating the website visually with a mouse, which presented many barriers for those navigating with a keyboard, voice dictation, or readaloud technology (e.g., barriers related to a lack of alternative text for visual files, poor website navigability and search functionality, etc.) (for complete project details and results see Brown, Aggarwal, Joslin, Williams-Habibi, \& Sivanesanathan, 2018). We met weekly as a team as we moved through the various project stages (i.e., building test cases, website testing, and synthesizing results). 


\section{WRITING PROCESS}

Kate facilitated the compilation of the project's technical findings into a co-authored report shared with relevant offices on campus and Akshay, Kate, Ryan, Sarah, and Vipusaayini wrote individual reflections on our project experiences that were gathered into a report for our student partners program. Alise then supported a process of consolidating this material into a case study and collectively revising for wider publication. To preserve privacy and reflect our collective work together, we decided to write in a plural voice rather than attach names to individual reflections.

\section{RELATED CONVERSATIONS IN THE LITERATURE}

Disability communities have long been advocating "Nothing About Us Without Us" that activities affecting our lives should involve people with disabilities in meaningful decisionmaking roles (Jorgensen, Bates, Frechette, Sonnenmeier, \& Curtin, 2011). However, in our experience, this demand has been largely ignored by our postsecondary institution, where initiatives affecting disabled communities on campus (e.g., compliance with accessibility legislation, delivery of disability-related accommodations) are often implemented with little proactive partnership with disabled students, staff, and faculty. Adopting a student-staff partnership approach is our way of responding to this long history of disability struggle for recognition, involvement, and structural change.

Emerging literature identifies opportunities for disability-related partnerships in postsecondary education: Disabled students are better supported in their learning when (a) instructors work closely with staff employed in campus disability offices (Austin \& Peña, 2017; Scott, Markle, Wessel, \& Desmond, 2016; Smith \& Buchannan, 2012), teaching and learning centres, and equity/diversity offices (Fovet, Mole, Jarrett, \& Syncox, 2014); (b) when disability offices work in collaboration with the library to ensure the accessibility of course material and library learning spaces (Arzola, 2016; Sanchez-Rodriguez, \& LoGiudice, 2018); and (c) when teaching and learning centres collaborate with disability offices to offer new faculty orientations, training, or other programs to advance accessible education (Behling \& Linder, 2017). Notably though, these partnerships are focused on (predominantly non-disabled) staff working more effectively with each other rather than involving disabled students.

While there is some evidence that user testing of university websites or user design in campus construction is happening elsewhere, these pilot projects tend to involve automated accessibility assessment tools (Ismailova \& Inal, 2018), a general (non-disabled) student population (Senol, Gecili, \& Durdu, 2014), disabled students as volunteer research participants (Sekovanić et al., 2012; Watson, Bartlett, Sacks, \& Davidson, 2013), or disabled students contributing without (it appears) financial compensation (Staeger-Wilson, Barnett, Mahoney, \& Sampson, 2012; Staeger-Wilson \& Sampson, 2012). It is exciting to see discussion of technology-focused projects in the student partnership literature, but again, disabled students and issues of accessibility are often left unconsidered (Handley, 2018; Prescott, Iliff, Edmondson, \& Cross, 2019).

Contrastingly, in our project, disabled students are fulsome collaborators and paid employees, extending the limited literature in this area (see the Student Web Accessibility Project described by Lewis et al., 2007). As one final point, it is important to note how disabled 
students are typically treated as "deficient" individuals requiring a range of service interventions (e.g., counselling, accommodations, transition programs, skills development, peer/faculty mentorship) to ensure retention, academic success, and employability (Bellman, Burgstahler, \& Ladner, 2014; Langley-Turnbaugh, Whitney, Lovewell, \& Moeller, 2014; Muller, 2006). Our partnership approach instead draws on disabled students' expertise to address barriers within the institutional environment.

\section{REFLECTIONS ON THE PROJECT}

\section{Successes}

\section{Contributing disabled student knowledge}

Scholarship on Students as Partners often describes students as bringing homogenous student knowledge with them to the partnership: “[student partners'] experience and expertise typically is in being a student. ... They understand where they and their peers are coming from" (Cook-Sather, Bovill, \& Felten, 2014, p. 15). While we certainly did bring "student" experiences, these were from a disability perspective. For example, although it may be a common experience for students to be time-crunched and need access to information quickly, many do not know what it is like for this information to not be readily available because of the inaccessibility of a website. It was our disability-specific student experiences that proved vital to the project (Staeger-Wilson \& Sampson, 2012). In contrast to Lewis et al. (2007), who describe hiring and training disabled and non-disabled student web accessibility consultants who are new to (in)accessibility, our project team had significant first-hand knowledge of disability, inaccessible educational environments, disability-related accommodations and services from the user perspective, and using assistive technology to reduce barriers (e.g., keyboard navigation, ChromeVox read-aloud application, Dragon Naturally Speaking speech recognition software). This knowledge facilitated our ability to work collaboratively in partnership and challenge deficit-based ideas of disability as we all had specific expertise (beyond that of "student" knowledge) to learn from and contribute.

\section{Personal learning}

Another success was that through team discussions, reading, and project implementation, we (a) acquired a greater understanding of provincial accessibility legislation, institutional compliance protocols, and inaccessibility from the perspective of team members with different disabilities; (b) developed more specialized expertise in digital accessibility, building user test cases, testing the assistive technology we use in daily life against these test cases, and observing and documenting results; and (c) gained confidence in voicing our own experiences and perspectives. One of us learned how to use a new assistive read-aloud technology that we now prefer over the one we initially used. Additionally, the project affirmed our interests in advancing accessibility as part of our ongoing/future careers, and several of us have since started new accessibility projects (e.g., a disability justice radio show, user testing for different projects, an accessible media certificate program). For example, one team member explained: 
This experience helped me realize that I would like to work with accessibility and mental health in the future to help create resources to benefit those like myself and my peers. This experience has made me a huge advocate for user testing for all projects focused on accessibility.

Another team member reflected:

Working on this project as a student with a disability has helped show me that I have the ability to contribute my experience and skills in a meaningful way. It has improved my confidence in seeking out further employment as I felt I was an important member of the project.

\section{Belonging}

A number of us have found university life particularly isolating as disabled students facing institutional barriers, and one of us felt this isolation as an international student. The friendships and community we developed over the course of the project, and the experience of having our disability knowledge affirmed as valuable, helped increase our sense of belonging on campus. One team member described their experience in this way:

Transitioning into university is already pretty challenging, but when you add a disability to this transition, it becomes even more difficult. From my experience, the university felt exclusive in its design and actions surrounding accessibility - making me feel a bit like an "outsider." In contrast, this project was very inclusive, accommodating, and overall a very positive experience. ... Contributing to the team and to making campus more accessible helped me feel more connected to McMaster, and pushed me a little further to that feeling of "belonging."

This affirms prior research on how disabled students' sense of belonging can be enhanced by facilitating positive connections between faculty, staff, and disabled peers (Vaccaro, Daly-Cano, \& Newman, 2015) - such as those cultivated in partnership-and by addressing an inaccessible and correspondingly unfriendly campus climate (Cowing, 2016; Fleming, Oertle, Plotner, \& Hakun, 2017). This latter point is especially significant as it suggests that pedagogical partnership projects that do not pay attention to and mediate issues of inaccessibility-both in the process of the partnership itself, as well as in the focus of the partnership work-may not have as much impact on disabled partners' sense of belonging in the university as those that seek to enhance accessibility.

\section{Affecting change on campus}

While macro/wider-scale impacts are less commonly reported in the partnership literature, which tends to instead emphasize individual-level benefits (Mercer-Mapstone et al., 2017), perhaps the most significant success of our project was affecting real change on campus. Results from our pilot project were delivered to our primary campus website/media developers 
and have been well-received, leading to additional user testing of new websites, changes in institutional website design (e.g., creation of mandatory fields for descriptive/alternative text for images, enhanced content heading structures, enhanced navigability), the development of feedback infrastructure, and ongoing efforts to consult with disabled users when reviewing learning management systems, university apps, and other online spaces. Prior to this project, user testing of campus technology was relatively unheard of, whereas now, colleagues are advocating for it to become standard practice, moving beyond compliance requirements to actual usability and inclusion (Staeger-Wilson \& Sampson, 2012). Our hope is for the full integration of user testing into our institutional website strategy. Making these changes has been personally impactful, as expressed in one of our reflections:

As a student with a learning disability, I am reminded of educational inaccessibility and frustrated by very fixable things on a daily basis. This ranges from course readings that are not compliant with screen readers, to poorly organized modules or course content, or to the basic format of exams and tests. I felt this project provided me with the opportunity to actually fix some of these things and make a meaningful difference to our campus that will directly affect me and many others now and in the future.

Another team member explained, "More often than not, my disability tends to take a back seat and can feel like a liability. Through this project, I was finally able to use my disability to help spur progress." Additionally, the disabled staff partners on the team have been encouraged to initiate several other collaborations, including an offshoot User Testing Pilot Program launched in the spring of 2020, resulting in an expanding number of positions specifically recruiting students with disabilities into meaningful employment to advance disability inclusion.

\section{Challenges}

\section{Recruitment}

Although the positions were advertised through our campus teaching and learning centre, equity office, disability office, and disabled student-run groups, we only received six applications for a total of four positions. We attribute this low response to a range of barriers: the distribution of the job posting, format/content of the standard student partner application process, the two-week application deadline, and the specialized skill-set we were seeking to recruit. Disabled students may be disinclined to identify with a disability, or worry about doing so, given the potential for social rejection and other negative ramifications (Riddell, Tinklin, \& Wilson, 2005). They may also be more likely to focus on the demands of academic work (especially when this involves time-consuming labour to coordinate accommodations) and avoid extra-curricular positions (Muller, 2006). Additionally, students may have felt uncertain about how to contribute to the project (e.g., students may have felt unsure what user testing is or of how to draw on their experiences of disability in an employment context). While the applications we did receive were excellent and led to the success of the project, the small applicant pool did limit the assistive technologies with which we were able to usability test, as we focused on those that team members were experts in through daily use. A more diverse 
applicant pool may have enabled us to test with additional technologies, or the same technology from multiple user perspectives.

\section{Time}

Creating a flexible work environment was essential to student participation in the project (Marquis, Jayaratnam, Mishra, \& Rybkina, 2018). As one partner reflected, "as an active student with a disability, taking on extra responsibilities is often very difficult, but as a Student Partner I never felt pressured and my team was very accommodating." That said, despite our best efforts to foster flexibility, completing the project by the time the student partners' contracts ended at the end of the academic semester was difficult. We succeeded in having the user testing complete, but not the authorship of deliverables (which resulted in most contributions to this stage being voluntary/unpaid). Although the literature indicates that partnerships routinely run into time/funding barriers (Marquis et al., 2016), we imagine that rigid term-based payment schedules are particularly challenging for projects seeking to engage disabled students.

\section{Co-designing a direction}

While the common struggle to "balanc[e] guidance and self-direction" (Marquis et al., 2016, p. 9) is noted in other partnership scholarship, what felt unique to our experience was how the autonomy offered by this project was new to some of us as disabled people (not just as students). As students, we are used to being micromanaged with guidelines and directives, and as disabled users, it's commonplace to access services without being consulted for our feedback. It was a bit of a learning curve for some of us to apply our own knowledge and opinions to the project in order to co-design a direction. As the staff partner coordinating the project reflected,

Disability had knocked down my confidence. I constantly doubted my ability to get things done and to meet deadlines as a recent undergraduate alumni in a new staff role, and this was compounded when others (especially student partners!) were counting on me.

This is an important example of how staff/faculty partners are not a homogenous group; some experience marginality in society and the academy, which can affect our participation in, and the potential risks of, partnership (Kupatadze, 2019; Marquis, Woolmer, Guitman, \& Nguyen, 2019). In this case especially, having the project fail could have had significant repercussions on a staff partner's contractually-limited employment and the institution's receptivity to disabled people's feedback and future user testing. Luckily, the hesitation of some members emboldened others to jump in with their expertise, and so we were able to collaborate across a range of un/certainties.

\section{CONCLUSION}

There are many ways that postsecondary institutions can respond to the demands of disability communities to be actively included in initiatives and decisions that affect us 
(Jorgensen et al., 2011). Involving disabled students in user testing specifically, and student pedagogical partnerships more generally, are two such opportunities that benefit the individual students involved, as well as the broader campus community. Our project adds to the growing literature on how student-faculty/staff partnerships contribute to greater equity on campus (Cook-Sather, 2018; Marquis et al., 2019; Mercer-Mapstone \& Bovill, 2019), especially the literature focused on epistemic justice and how pedagogical partnerships can recognize and affirm the knowledges of students from equity-seeking groups (de Bie, Marquis, Cook-Sather, \& Luqueño, 2019). Moreover, our work supports the de-homogenization of student/staff partners by highlighting specific experiences of disabled participants and impacts on campus accessibility. Moving forward, we encourage partnership programs to proactively address barriers-not only in recruitment, but throughout the entire partnership process and experience-that may be restricting the participation of disabled students and those from other equity-seeking groups (Bindra et al., 2018; Felten et al., 2013; Marquis et al., 2016, 2018; Mercer-Mapstone \& Bovill, 2019). Non-academic/non-teaching staff, such as accessibility specialists and those employed in campus disability and equity offices, might also be invited to become more involved in relevant pedagogical partnerships with students (Mercer-Mapstone et al., 2017). Expanding partnership beyond the classroom and curricula is an important area for ongoing exploration. As our case study attests, there are many aspects of campus life that could benefit from partnership, especially with disabled students, including technology and communications, institutional policy, and activities to ensure legislative compliance and enhance accessibility across the university.

\section{ACKNOWLEDGEMENTS}

We are grateful to have received funding from the Student Partners Program of the Paul R. MacPherson Institute for Leadership, Innovation, and Excellence in Teaching at McMaster University, and some additional financial support from the Accessibility Working Group of McMaster's President's Advisory Committee on Building an Inclusive Community. We also wish to thank Clark Cipryk, our campus Web Accessibility Specialist, and Anne Pottier, Chair of the McMaster Accessibility Council, for their support, and Nick Marquis, Learning Technology Consultant within the Faculty of Social Sciences, for his proactive, grassroots work within his own Faculty and the university broadly to encourage the creation of a campus strategic plan for enhancing the accessibility of information technology.

\section{NOTES ON CONTRIBUTORS}

Kate Brown supported this project in her role as the accessibility projects coordinator in McMaster's Equity and Inclusion Office, and is now the accessibility program manager in this office. She is a graduate of McMaster University's Honours Bachelor of Arts program in Indigenous Studies and Linguistics.

Alise de Bie supported the user testing project in their role as the accessibility projects facilitator in McMaster's Equity and Inclusion Office. They were also completing their doctoral work at the 
time. Alise is currently a postdoctoral research fellow in McMaster's Paul R. MacPherson Institute for Leadership, Innovation and Excellence in Teaching.

Akshay Aggarwal's student partner role involved designing the user testing template and providing technical training and support throughout. Akshay began his MBA at McMaster University and recently completed it through the Schulich School of Business at York University. He is currently working at Ernst \& Young as a senior consultant in their information technology advisory practice.

Ryan Joslin contributed to this project as a student partner. He holds an Honours BA in political science from McMaster University and is currently completing a Graduate Certificate in Accessible Media Production at Mohawk College.

Sarah Williams-Habibi contributed to this project as a student partner. She is currently in the Combined Honours Arts \& Science and Psychology, Neuroscience \& Behaviour Program at McMaster University. Sarah is also the creator and host of "Spoons", a radio show dedicated to celebrating music and ideas from folks who have identities within the larger disability justice movement.

Vipusaayini Sivanesanathan contributed to this project as a student partner. She holds an Honours BSc in life sciences from McMaster University and an Honours BA in philosophy from York University. She is currently pursuing an MA in philosophy at Queen's University.

\section{REFERENCES}

Accessibility for Ontarians with Disabilities Act, 2005, SO 2005, c11. Retrieved from https://www.ontario.ca/laws/statute/05a11

Arzola, R. (2016). Collaboration between the library and office of student disability services: Document accessibility in higher education. Digital Library Perspectives, 32(2), 117-126. https://doi.org/10.1108/DLP-09-2015-0016

Austin, K. S., \& Peña, E. V. (2017). Exceptional faculty members who responsively teach students with autism spectrum disorders. Journal of Postsecondary Education and Disability, 30(1), 17-32. https://files.eric.ed.gov/fulltext/EJ1144609.pdf

Bates, T. (2017, November 11). Why does Canada have so much online learning? Online Learning and Distance Education Resources [Blog]. Retrieved from https://www.tonybates.ca/2017/11/11/why-does-canada-have-so-much-onlinelearning/

Behling, K., \& Linder, K. E. (2017). Collaborations between centers for teaching and learning and offices of disability services: Current partnerships and perceived challenges. Journal of Postsecondary Education and Disability, 30(1), 5-15. https://files.eric.ed.gov/fulltext/EJ1144608.pdf

Bellman, S., Burgstahler, S., \& Ladner, R. (2014). Work-based learning experiences help 
students with disabilities transition to careers: A case study of University of Washington projects. Work, 48(3), 399-405. https://doi.org/10.3233/WOR-131780

Bevan, N., \& Petrie, H. (2009). The evaluation of accessibility, usability and user experience. In C. Stepanidis (Ed.), The universal access handbook (334-349). Boco Raton, Florida: CRC Press.

Bindra, G., Easwaran, K., Firasta, L., Hirsch, M., Kapoor, A., Sosnowski, A., Stec-Marksman, T., \& Vatansever, G. (2018). Increasing representation and equity in students as partners initiatives. International Journal for Students as Partners, 2(2), 10-15. https://doi.org/10.15173/ijsap.v2i2.3536

Brown, K., Aggarwal, A., Joslin, R., Williams-Habibi, S., \& Sivanesanathan, V. (2018). User testing for web accessibility project report. Prepared for the McMaster Accessibility Council and McMaster Media Production Services by the Equity and Inclusion Office. Hamilton, Ontario. Retrieved from http://hdl.handle.net/11375/25177

Cook-Sather, A. (2018). Listening to equity-seeking perspectives: How students' experiences of pedagogical partnership can inform wider discussions of student success. Higher Education Research \& Development, 37(5), 923-936. https://doi.org/10.1080/07294360.2018.1457629

Cook-Sather, A., Bovill, C., \& Felten, P. (2014). Engaging students as partners in learning and teaching: A guide for faculty. California: Jossey-Bass.

Cowing, J. (2016). Access, tradition and belonging at "the Alma Mater of the Nation". In J. Silverman \& M. M. Sweeney (Eds.), Remaking the American college campus: Essays (191-203). North Carolina: McFarland \& Company, Inc.

de Bie, A., Marquis, E., Cook-Sather, A., \& Luqueño, L. (2019). Valuing knowledge(s) and cultivating confidence: Contributing to epistemic justice via student-faculty pedagogical partnerships. In J. Hoffman, P. Blessinger, \& M. Makhanya (Eds.), International perspectives in higher education: Strategies for fostering inclusive classrooms (35-48). Emerald Group Publishing Ltd.

Digital education strategies. (2018) Professional web accessibility auditing made easy. Toronto: The Chang School, Ryerson University. Retrieved from https://pressbooks.library.ryerson.ca/pwaa/

Felten, P., Bagg, J., Bumbry, M., Hill, J., Hornsby, K., Pratt, M., \& Weller, S. (2013). A call for expanding inclusive student engagement in SoTL. Teaching and Learning Inquiry, 1(2), 63-74. Retrieved from http://www.jstor.org/stable/10.2979/teachlearninqu.1.2.63

Fleming, A. R., Oertle, K. M., Plotner, A. J., \& Hakun, J. G. (2017). Influence of social factors on student satisfaction among college students with disabilities. Journal of College Student Development, 58(2), 215-228. https://doi.org/10.1353/csd.2017.0016

Fovet, F., Mole, H., Jarrett, T., \& Syncox, D. (2014). Like fire to water: Building bridging collaborations between disability service providers and course instructors to create user friendly and resource efficient UDL implementation material. Collected Essays on Learning and Teaching, 7(1), 68-75. https://doi.org/10.22329/celt.v7i1.3999

Handley, F. (2018). Students as partners in technology initiatives: How does the technology aspect affect partnerships. Paper presented at the Association for Learning Technology Annual Conference 2018, Manchester, UK. Retrieved from 
https://altc.alt.ac.uk/2018/sessions/students-as-partners-in-technology-initiatives-howdoes-the-technology-aspect-affect-partnerships-and-how-can-we-make-the-most-ofthis-18-129/members/

Interactive Accessibility. (2015). Usability and accessibility testing. Retrieved from https://www.interactiveaccessibility.com/services/usability-accessibility-testing

Ismailova, R., \& Inal, Y. (2018). Accessibility evaluation of top university websites: A comparative study of Kyrgyzstan, Azerbaijan, Kazakhstan and Turkey. Universal Access in the Information Society, 17(2), 437-445. https://doi.org/10.1007/s10209-017-0541-0

Jorgensen, C. M., Bates, K., Frechette, A. H., Sonnenmeier, R. M., \& Curtin, J. (2011). “Nothing about us without us": Including people with disabilities as teaching partners in university courses. International Journal of Whole Schooling, 7(2), 109-126. Retrieved from https://files.eric.ed.gov/fulltext/EJ961506.pdf

Kupatadze, K. (2019). Opportunities presented by the forced occupation of liminal space: Underrepresented faculty experiences and perspectives. International Journal of Students as Partners, 3(1), 22-33. https://doi.org/10.15173/ijsap.v3i1.3744

Langley-Turnbaugh, S., Whitney, J., Lovewell, L., \& Moeller, B. (2014). Benefits of research fellowships for undergraduates with disabilities. Council On Undergraduate Research Quarterly, 35(2), 39-45. Retrieved from http://www.cur.org/assets/1/23/winter14 textandcoverfinalweb.pdf\#page=41

Lewis, K., Yoder, D., Riley, E., So, Y., \& Yusufali, S. (2007). Accessibility of instructional web sites in higher education. Educause Quarterly, 30(3), 29-35. Retrieved from https://er.educause.edu/Lmedia/files/articles/2007/7/eqm0734.pdf?la=en\&hash=462519605B11FC6DD8EAA686 D7552268A17AD123

Marquis, E., Jayaratnam, A., Mishra, A., \& Rybkina, K. (2018). "I feel like some students are better connected": Students' perspectives on applying for extracurricular partnership opportunities. International Journal for Students as Partners, 2(1), 64-81. https://doi.org/10.15173/ijsap.v2i1.3300

Marquis, E., Puri, V., Wan, S., Ahmad, A., Goff, L., Knorr, K., Vassileva, I., \& Woo, J. (2016). Navigating the threshold of student-staff partnerships: A case study from an Ontario teaching and learning institute. International Journal for Academic Development, 21(1), 4-15. https://doi.org/10.1080/1360144X.2015.1113538

Marquis, E., Guitman, R., Nguyen, E., \& Woolmer, C. (2020). 'It's a little complicated for me': Faculty social location and experiences of pedagogical partnership. Higher Education Research \& Development, 1-14. https://doi.org/10.1080/07294360.2020.1806789

Mercer-Mapstone, L., \& Bovill, C. (2019). Equity and diversity in institutional approaches to student-staff partnership schemes in higher education. Studies in Higher Education, 117. https://doi.org/10.1080/03075079.2019.1620721

Mercer-Mapstone, L., Dvorakova, S. L., Matthews, K. E., Abbot, S., Cheng, B., Felten, P., Knorr, K., Marquis, E., Shammas, R., \& Swaim, K. (2017). A systematic literature review of students as partners in higher education. International Journal for Students as Partners, 1(1). https://doi.org/10.15173/ijsap.v1i1.3119

Muller, L. (2006). Research collaboration with learning-disabled students. Journal of College

Brown, K., de Bie, A., Aggarwal, A., Joslin, R., Williams-Habibi, S. \& Sivanesanathan, V. (2020). 
Science Teaching, 36(3).

Prescott, J., Iliff, P., Edmondson, D. J., \& Cross, D. (2019). Students as co-creators of a mobile app to enhance learning and teaching in HE. In A. F. Baruch \& H. M. Tal (Eds.), Mobile technologies in educational organizations (96-116). United States: IGI Global.

Riddell, S., Tinklin, T., \& Wilson, A. (2005). Disabled students in higher education:

Perspectives on widening access and changing policy. London \& New York: Routledge. https://doi.org/10.4324/9780203087121

Sanchez-Rodriguez, N. A., \& LoGiudice, J. (2018). Building bridges: Fostering dynamic partnerships between the library department and office of student disability services in higher education. Journal of Access Services, 15(4), 142-160. https://doi.org/10.1080/15367967.2018.1520640

Scott, S., Markle, L., Wessel, R. D., \& Desmond, J. (2016). Disability services partnerships with faculty members. Journal of Postsecondary Education and Disability, 29(3), 215-220. Retrieved from https://files.eric.ed.gov/fulltext/EJ1123792.pdf

Sekovanić, V., Vukovac, D. P., \& Podbojec, Z. (2012). Usability case study of adapted e-learning course for dyslexic students. Proceedings of the 5th International Conference of Education, Research and Innovation. Madrid, Spain.

Senol, L., Gecili, H., \& Durdu, P. O. (2014, June 23). Usability evaluation of a Moodle based learning management system. EdMedia+ Innovate Learning (850-858). Association for the Advancement of Computing in Education (AACE). Retrieved from https://www.learntechlib.org/primary/p/147592/

Smith, R. E., \& Buchannan, T. (2012). Community collaboration, use of universal design in the classroom. Journal of Postsecondary Education and Disability, 25(3), 259-265. Retrieved from https://files.eric.ed.gov/fulltext/EJ994291.pdf

Staeger-Wilson, K., Barnett, C., Mahoney, S., \& Sampson, D. H. (2012). Planning for an inclusive campus recreation facility and program. Recreational Sports Journal, 36(1), $37-$ 44. https://doi.org/10.1123/rsj.36.1.37

Staeger-Wilson, K., \& Sampson, D. H. (2012). Infusing JUST design in campus recreation. Journal of Postsecondary Education and Disability, 25(3), 247-252. Retrieved from https://files.eric.ed.gov/fulltext/EJ994289.pdf

United Nations. (2006). Convention on the rights of persons with disabilities (CRPD) - Article 9 - Accessibility. Retrieved from https://www.un.org/development/desa/disabilities/convention-on-the-rights-ofpersons-with-disabilities/article-9-accessibility.html

Vaccaro, A., Daly-Cano, M., \& Newman, B. M. (2015). A sense of belonging among college students with disabilities: An emergent theoretical model. Journal of College Student Development, 56(7), 670-686. https://doi.org/10.1353/csd.2015.0072

Wang, A. X., \& Schrager, A. (2017, September 27). It's the end of the university as we know it. Quartz. Retrieved from https://qz.com/1070119/the-future-of-the-university-is-in-the-air-and-in-the-cloud/

Watson, E., Bartlett, F., Sacks, C., \& Davidson, D. L. (2013). Implementing universal design: A 
collaborative approach to designing campus housing. Journal of College \& University Student Housing, 40(1), 158-171. Retrieved from

http://www.nxtbook.com/nxtbooks/acuho/journal_vol39no2/index.php\#/132 